\title{
«VIH/sida awajún»: nociones y experiencias de enfermedad y daño en un contexto de epidemia en la Amazonía peruana
}

\author{
María Ximena Flores Rojas \\ (iD) https://orcid.org/0000-0001-6099-3866 \\ Universidade Federal do Rio de Janeiro \\ ximeflores.r@gmail.com
}

RESUMEN

Desde el año 2002, de acuerdo con los relatos de algunas familias awajún, empezaron a correr los rumores sobre una nueva enfermedad llamada «sida» en el distrito de El Cenepa. Esta condición de origen apách o no indigena se incorporó en la cotidianidad la población awajún como parte de sus experiencias de enfermedad (jata) y brujería (waweamu), generando las nociones de «jata sida» $y$ «waweamu con síntoma de sida». La mayoría de los estudios sobre VIH/sida en pueblos indigenas suelen abordar esta condición desde enfoques biomédicos o epidemiológicos. Este artículo presenta otras dimensiones posibles para pensar el VIH/sida en contextos indigenas. Partiendo del complejo conocimiento awajún sobre el cuerpo amazónico y las fuerzas que lo afectan, este artículo busca entender las nociones y experiencias de «enfermedad» y «brujeria» que la población awajún usa al hablar de VIH/sida.

Palabras clave: VIH, sida, awajún, enfermedad, brujería y cuerpo. 


\section{«HIV/aids awajun»: Notions and experiences of disease and sorcery in the context of an epidemic in the Peruvian Amazon}

ABSTRACT

According to the memories of some Awajun families, since 2002 rumors about a new disease called "Aids», began to appear in the El Cenepa district. This apách, or non-indigenous condition, was incorporated into Awajun daily life as part of their experiences with illness (jata) and sorcery (waweamu), generating the notions of «jata Aids» and "waweamu with Aids symptoms». Far from a biomedical or epidemiological approach, this article presents other possible dimensions of thinking about HIV/aids in indigenous contexts. From the complexity of Awajun knowledge about their bodies and the forces that affect him. This article aims to understand the notions and experiences of illness and sorcery that the Awajun population have regarding HIV/aids.

Keywords: HIV/Aids, Awajun, sickness, sorcery, body. 


\section{INTRODUCCIÓN}

Los awajún son el segundo pueblo indígena más numeroso de la Amazonía peruana. Antiguamente conocidos como aents («personas verdaderas»), o shiwang («personas enemigas»), recibieron el etnónimo de «aguaruna» ante la sorpresa de los españoles de ver varones tejedores de ropa y utensilios con fibras de chambira (Astrocaryum vulgare) y de algodón (Gossypium barbadense L.). Asentados especialmente en cinco regiones del Perú, pertenecen a la familia lingüística jíbaro junto con los pueblos achuar, shuar, wampis y pueblos con prácticas similares como los canelos (de habla kichwa), candoshi y shapra (de habla candoa).

Los awajún del distrito de El Cenepa, en la provincia de Condorcanqui de la región Amazonas, dan la bienvenida a su territorio con un paisaje de bosque tupido acompañado por montañas, pongos y seres mitológicos. La estrechez de sus ríos fue escenario de crónicas de viajeros y misioneros que lo describieron como un territorio hostil, hogar de los «más crueles infieles de esta parte de América», «por naturaleza guerreros y por lo tanto violentos» (Espinoza, 2009, p. 133). Lejos de esta imagen de salvajismo, los y las yáunchugmuun o antiguos abuelos y abuelas awajún pasaron a sus hijos otra historia de negociaciones con esos apách, como se denomina a las personas no indígenas que llegaron a su territorio. Estos nuevos vecinos (caucheros, comerciantes, misioneros y docentes) trajeron al territorio awajún mercaderías, dinero, relaciones de explotación y nuevas enfermedades. Estas enfermedades no indígenas han sido, históricamente, un vector de muerte y devastación en el territorio awajún.

«Mi hijo»; «mi esposo»; «mi hermana»; «mi hija»; «la hija de Germán»; «a mí», fueron las expresiones con las que iniciaban las historias de VIH/sida en las comunidades awajún del distrito de El Cenepa. Desde 2002, de acuerdo con los relatos de algunas familias awajún, empezaron a correr los primeros rumores sobre 
una nueva enfermedad apách llamada «sida», traída por jóvenes que retornaban de las ciudades y personas no indígenas. A partir de entonces, el incremento de casos de VIH y de sida fue una de las principales preocupaciones de las familias awajún. De acuerdo con los registros de la Micro Red de Salud Huampami (2018) y de la Red de Salud Condorcanqui (Pintado, 2016) se presume que la primera muerte asociada al "sida" en el distrito de El Cenepa ocurrió entre los años 2005 y 2007. En contraste a los problemas de registro del Ministerio de Salud, para las familias awajún las muertes asociadas al "sida" se hicieron evidentes a partir del 2010. «El 2010 decían que tenían sida, sida y muchos morían. El cementerio se quedó llenito con muertes de sida», recordaba un joven especialista en plantas de la comunidad de Kusu Kubaim. Entre enero de 2010 y junio de 2018, se diagnosticaron 196 casos de VIH en el distrito de El Cenepa (Red de Salud Condorcanqui 2018). Ello quiere decir que aproximadamente el 1,9\% de la población de este distrito es seropositiva. Esta incidencia se duplica en algunas comunidades, donde al menos el 4,6\% —e incluso el 7\% — de su población ha sido diagnosticada con VIH por los puestos de salud (Red de Salud Condorcanqui, 2018).

Conocí el distrito de El Cenepa el año 2014. Junto a un equipo de antropólogos entré a este territorio para generar insumos que mejoren la atención del $\mathrm{VIH} /$ sida en esta población. Entre abril y junio de 2018, retorné a este distrito con el deseo de volver a trabajar con las familias awajún de las comunidades de Kusu Kubaim, Kusu Pagata y Huampami. Mi objetivo era pensar las nociones y experiencias awajún asociados al VIH/sida desde una aproximación etnográfica. Utilizo la conjunción VIH/sida en este artículo por el uso indistinto que se suele dar de las palabras VIH y sida en las comunidades awajún. Durante mi trabajo de campo percibí que la diferencia serológica entre VIH y sida no era algo relevante para las familias awajún con las que trabajé. Por el contrario, ellos usaban otros criterios para definir los malestares que los afligían.

No existe una sola historia sobre el VIH/sida para las familias con quienes trabajé. En las primeras conversaciones con las familias las palabras "jata" y "waweamu" comenzaron a hacérseme poco a poco evidentes. Por un lado, jata, traducida al castellano como «enfermedad» o «muerte», se había conjugado con las palabras no indígenas de VIH y de sida, formando las expresiones "jata sida", "jata VIH" o "setash" para nombrar a la nueva enfermedad que se estaba diagnosticando en los establecimientos de salud de las comunidades. Por otro lado, la palabra waweamu, traducida como «daño»o «brujería», estaba asociada al complejo universo de relaciones de afectación entre personas awajún. Donde tunchis «brujos» o especialistas rituales estaban causando el daño con síntomas 
de sida. En este artículo presento, desde la voz de mis interlocutores, estas experiencias de enfermedad (jata) y de daño (waweamu) asociadas al VIH/sida awajún.

Durante los meses de trabajo de campo, acompañé a quince familias en las comunidades de Kusu Kubaim, Kusu Pagata y Huampami. Todas las entrevistas fueron realizadas en idioma awajún con la ayuda de una traductora espontánea. Mis principales interlocutores fueron las madres awajún, a quienes también acompañé en sus actividades diarias en la cocina, en la chacra y en el cuidado de sus hijos; los y las abuelas awajún, llamados muun ; los especialistas de los establecimientos de salud y los conocedores de plantas. La apertura emocional y confianza de mis anfitriones fue muy significativa para mí y siempre les estaré agradecida. Para mantener el anonimato de mis interlocutores he cambiado sus nombres personales y familiares. Asimismo, en ningún caso menciono su comunidad de residencia.

\section{LA NOCIÓN DE «ENFERMEDAD»Y EL ABORDAJE DEL VIH EN CONTEXTOS INDÍGENAS AMAZÓNICOS}

Parto de entender la noción de «enfermedad» desde el concepto inglés de sickness de Kleinman (1978), como un proceso amplio de experiencia vivida que tiene como protagonista al sujeto, no solo desde su dimensión biológica sino, como sustenta Menéndez (2015), inserto en procesos sociales, políticos, económicos y cosmológicos. Como enfatiza Minayo (1991, p. 233), la enfermedad es una realidad construida y el enfermo un personaje social. Pensar los procesos de salud-enfermedad únicamente desde variables anatómicas-físicas o con medidas cuantitativas constituye una miopía frente a lo social y una falla frente a la realidad que se pretende estudiar.

El trabajo de Langdon (2014) es aquí un referente para pensar la noción de «enfermedad» en la Amazonía. En el caso de los indígenas siona, Langdon nos presenta las «enfermedades siona» como eventos colectivos, políticos y dramáticos que implican momentos de interpretación, de diagnóstico y de búsqueda de tratamientos. «El significado de la enfermedad es construido a través de una lógica etiológica donde se buscan causas que van más allá del cuerpo biológico, dislocando el significado de enfermedad a contextos cosmológicos, sociales y morales» (p. 124). Como sugiere Alves (1993), cuando los síntomas clínicos se transforman en impresiones sensibles de un colectivo, surge la noción de «enfermedad» (Alves, en Agostini, 2018, p. 204). 
La «enfermedad», en este artículo, no responde a una experiencia atemporal, ahistórica, ni universal. La memoria de los pueblos indígenas amazónicos suele distinguir los tiempos donde las enfermedades eran conocidas y tratables, en contraste con el tiempo del contacto. La enfermedad como herencia del «blanco» trajo lo que se conocen actualmente como las enfermedades no indígenas (Unesco, 2014, p. 33). Buchillet (2004), Albert y Alcida (2002), Kopenawa y Albert (2015), han abordado muy profundamente estas cosmologías de contacto.

De la cercanía con los no indígenas o blancos llegaron a los territorios indígenas «las enfermedades del sexo», entre ellas el VIH (Unesco, 2014). Ese fue el caso de los pueblos kanamari, terena, xokléng y bakairi de Brasil, los wayuu de Colombia, los warao de Venezuela, los yines, shipibo-conibo, awajún y wampis del Perú, entre otros (Castro, 2017; Minsa y UNFPA, 2009; Pina de Barros, 2000; Santander y Mora, 2015; Texeira, 2004; Unesco, 2014; Wiik, 2001).

En su mayoría, los estudios biomédicos sobre el VIH en pueblos indígenas suelen coincidir en la identificación de factores (externos e internos) de vulnerabilidad a partir de la comparación de las prácticas y conocimientos indígenas en contraste con los discursos biomédicos del VIH y del sida. A los factores externos asociados a la inequidad social, violencia de género, falta de acceso a la información, servicios de salud precarios, migración y diversas formas de violencia estructural, se suman factores internos como el inicio sexual precoz, el uso de plantas medicinales, el limitado uso de preservativo, entre otros. Estos últimos comportamientos se creen inherentes a la población indígena y justifican su limitada atención en el sistema biomédico (SIPIA y ONUSIDA 2016). La mayoría de los estudios realizados con población indígena peruana sobre el VIH/ sida ha seguido este interés epidemiológico (Orellana y Alva, 2012; Orellana, Alva, Cárcamo y García, 2013; Ormaeche, Whittembury, Pun y Suárez-Ognio, 2012; Portocarrero, 2015; Zavaleta, Mujica, Ypanaqué y Cueva, 2007).

Otros estudios, en cambio, apuestan por abordar el VIH/sida desde el cuerpo, la vida y la experiencia de sus protagonistas. Minsa y UNFPA (2009), en el caso de los pueblos yine y shipibo-conibo, del Perú, presenta la afectación del «principio vital» entre los signos de enfermedad asociados al VIH. El caso wayuu de Colombia, estudiado por Castro (2017, p. 237), al VIH, también llamado «enfermedad», se percibe como un regalo de los no indígenas que afecta las dimensiones sensibles del cuerpo wayuu y la vida después de la muerte. Los wayuu seropositivos pierden los privilegios que deberían recibir al morir "por su comportamiento en vida»; los vecinos no quieren tocar sus cadáveres y, por ello, no son purificados para su ingreso al jepirra, traducido como «paraíso». Estos casos etnográficos parecen 
coincidir con la propuesta de Wiik (2001, p. 6), de ver el cuerpo, los procesos corporales y las actitudes tomadas con relación a la enfermedad como un proceso de reproducción de la sociedad a través de la historia. Wiik, propone estudiar el VIH a través de la agencia de la persona y las mudanzas sociales.

En el caso de la población awajún del Perú, los estudios sobre el VIH han tenido por objetivo presentar propuestas de salud pública (Pintado, 2016; Lazo, 2014; Huamán, Gushikuen, Benites, Quiroz \& García, 2017) o presentan las nociones awajún sobre el VIH/sida como modelos explicativos indígenas (Chávez, 2019) o como a representaciones sociales (Medina 2019). Tomando distancia de estos aportes. Mi intención es enfocarme en la percepción de las propias familias awajún frente al VIH/sida. Deseo explorar las experiencias awajún que se tejen en torno al VIH/sida no como modelos interpretativos sino como parte de nuevas nociones de enfermedad que se construyen continuamente.

\section{LA AFECTACIÓN DEL CUERPO AWAJÚN}

Según la clásica etnografía de Brown (1984) y las concepciones de los abuelos con quienes conversé, la persona awajún llamada aént está conformada por el iyásh y el wakán. El iyásh corresponde a los aspectos más físicos de la corporalidad de las personas, mientras el wakán corresponde a los aspectos espirituales. En el distrito de El Cenepa, el iyásh era traducido en castellano como «cuerpo» y wakán como «alma». Similar a una botella de Klein (Lévi-Strauss, 1986) o una banda de Möbius, la persona y sus múltiples aspectos son como pliegues, donde lo material e inmaterial, lo de adentro y lo de fuera no se separan de manera dicotómica, sino que influyen entre sí produciendo continuamente a la persona, su cuerpo y su alma.

Para lograr «vivir bien», «vivir en salud», es necesario formar a la persona awajún en su multiplicidad. La vida cotidiana en las comunidades awajún es la demostración de este proceso de formación continuo del iyásh y del wakán. Las personas crecen por medio de la acumulación de conocimientos dados por sus parientes. Las madres, padres y abuelos hacen crecer el cuerpo de sus hijos a través de prácticas como: el uso de plantas para la formación en el vientre, la preparación de la madre para el parto, el entierro de la placenta en el suelo de la casa familiar, el antiguo proceso de covada, el uso ritual de las hojas de piripiri (Eleuterina bulbosa) y de la grasa de oso hormiguero (vermilingua) en la formación los huesos de los niños y niñas, los resguardos de búsqueda de visión futura y guerrera de los jóvenes, entre otros. Concepciones semejantes han sido 
analizadas en otros pueblos de la Amazonía (Belaunde, 2001, 2005; McCallum, 1998; Seeguer, Da Matta y Viveiros de Castro, 1979).

Ser una persona «sana» para los awajún es, en consecuencia, tener el cuerpo fuerte; poder realizar las actividades diarias, participar en la chacra o cultivo, ir a estudiar, viajar, estar en las actividades de ocio, y sobre todo, compartir la comida con los parientes. Como presenta Gow (1998), en el caso yine la comida es un circuito de producción y de circulación asociado con las relaciones de parentesco. La persona a través de la comensalidad se sabe miembro de una familia y reconoce a los demás como parientes. Por el contrario, estar enfermo es un estado de negación de esta vida cotidiana. Derivado de la raíz awajún ját, el jata, traducido al español como «enfermedad» o «muerte» habla del estado «donde la muerte amenaza» (Priest 1993, p. 54), o en palabras de una madre awajún, el estado donde la persona «empieza a no vivir».

Para los abuelos awajún, el origen de este estado próximo a la muerte se remonta a la llegada de los apách o personas no indígenas. Antes jata atsú, eran las palabras del muиn Kumpam cuando recordaba que anteriormente «no había enfermedad» y que los awajún vivían «sanos». Para el muun Kumpam el «tiempo de no enfermedad» terminó con la llegada de comerciantes y misioneros (evangélicos y católicos) que trajeron nuevas enfermedades a las que los awajún tuvieron que aprender a responder (Flores, 2019).

«Primero fue sarampión, luego fiebre amarilla y ahora estamos en tiempo de sida» , me decía un joven awajún conocedor de plantas medicinales. Así también lo recordaba el muun Santiago:

—Muun Santiago: No me acuerdo cuándo llegó. Antes no había enfermedad ni medicamentos, nos curábamos con ajeng (Zingiber officinale). Antes, no había jata. Llegaron los gringos y [ellos] trajeron la enfermedad apách.

-Ximena: ¿apách?

—M: ¡Apách es [una persona] como tú! Dicen que gringo, gringo, alemán creo; con barba, altos, blancos. Ellos llegaban a comprar tinte de tatuaje. Vinieron cinco, diez, ¡sus esposas también llegaban! Cuando llegaban gringos, no sé qué enfermedad traían, ¡de ahí todos enfermaban!

-X: ¿Y ahora hay esas enfermedades?

-M: ¡Silla! [la esposa del abuelo Santiago ríe a carcajadas y rápidamente cuenta a sus hijos el error de pronunciación de su padre. El abuelo Santiago ríe y se corrige] ¡Ahora más de lo que se enferman es con sida y tunche [brujería]!

Con la llegada de estas nuevas enfermedades, el cuerpo y los sistemas de diagnóstico y tratamiento awajún también se transformaron. Los especialistas 
sanitarios y las personas con quienes conversé eran enfáticos en hacerme entender que las enfermedades apách funcionaban de forma distinta en sus cuerpos. Para el pensamiento awajún, sus cuerpos eran diferentes que los de los apách, por ello, los abuelos recomendaban no comer todo lo que los no indígenas comían ni utilizar la medicina apách de la manera como los apách la utilizaban. Por ejemplo, pude observar que las familias awajún utilizaban muchos fármacos, pero no seguían las recetas recomendadas por los profesionales de salud apách sino, por el contrario, solían seguir las recomendaciones de los técnicos sanitarios awajún. Estos especialistas recetaban combinaciones de fármacos que eran vistas como más eficientes para atender las «enfermedades awajún». Así me explicó un técnico sanitario awajún: «En la ciudad no te van a dar así [medicamentos] combinados. Cuando tú estás enfermo con, por ejemplo, fiebre tifoidea, aquí yo te voy a curar como en la zona, con cuatro inyecciones [a la vez]. ¡No tengas miedo!».

La habilidad de los técnicos sanitarios awajún de recetar tratamientos exclusivos para los cuerpos awajún era muy apreciada por las familias. En las comunidades que visité, varios técnicos sanitarios tenían la fama de curar, en pocos días, cualquier afección con una mezcla exclusiva de medicamentos apách. El consumo de estos fármacos era para los awajún una forma de corroborar qué tipo de enfermedad tenían. Por ejemplo, si el medicamento funcionaba, la persona confirmaba que tenía esa enfermedad. Si, por el contrario, el medicamento no funcionaba, se seguía probando otras pastillas, inyectables y plantas medicinales hasta lograr el alivio de los síntomas. Sin embargo, cuando la cura era esquiva, las sospechas de brujería o waweamu aparecían.

El waweamu, traducido al castellano como «daño»o «brujería», es reconocido como un peligro inherente a toda persona awajún. Los tunchis o brujos son los responsables de esta amenaza de muerte. Según las familias awajún, los tunchis son especialistas con capacidades ambiguas. Pueden diagnosticar y curar todo tipo de dolencia; pero a la vez, pueden causar cualquier enfermedad a través de los dardos de daño tséntsak que ellos mismos crean y alojan en las dimensiones sensibles del cuerpo awajún (Brown, 1984; Priest, 1993). El cuerpo awajún es penetrado por los dardos de daño que afectan el wakán. Si estos virotes de brujería no son extraídos rápidamente, el wakán comprometiendo al iyásh causa la muerte de la persona.

El cuerpo amazónico en su multiplicidad es en consecuencia uno de los protagonistas de las experiencias de la enfermedad. Albert y Goodwin (1997, pp. 44-45), por ejemplo, presentan la enfermedad Yanomami como una agresión hacia los componentes inmateriales de la persona. La «imagen esencial» es 
afectada (herida, quemada, envenenada, amarrada, etcétera) y pasa a dominar el «comportamiento de enfermo» en la persona. Para evitar este estado de pérdida de razón, el enfermo, su familia y su aldea analizan y reconstruyen sus relaciones con los humanos y no humanos peligrosos que tienen alrededor. Entender la experiencia de «enfermedad» de un pueblo amazónico implica, entonces, conocer la afectación de este cuerpo, entendido como una malla relacional producida en relación con otros sujetos, substancias, espíritus y fuerzas vitales que se manejan durante los ciclos de vida por las familias (Flores, 2019).

Los cambios históricos actualizan la creatividad de los especialistas indígenas. Por ejemplo, en el caso de los tunchis awajún, actualmente se les acusa de saber causar las enfermedades de origen apách, como: tuberculosis, gastritis, VIH/sida, entre otros, a través de sus dardos tséntsak. En consecuencia, como veremos a continuación, una enfermedad de origen apách como el VIH/sida, al incorporarse en la cosmovisión y cuerpo awajún se transforma en un padecimiento propiamente awajún. El muun Rubio, quien perdió a gran parte de su familia en la década de 1950 a causa de la epidemia de sarampión, me explicó esta doble causalidad, de enfermedad y de daño, asociada al VIH/sida.

Antes no existía enfermedad [jata] de sida. A veces las personas se iban a trabajar, se acostaban y así han traído. También dicen que ahora el tunchi hizo eso. Él tiene tséntsak de VIH. Eso están haciendo, ipor eso se mueren las personas! (muun Rubio, 86 años, 2018).

\section{EL VIH/SIDA ENTRE LOS AWAJÚN DEL DISTRITO DE EL CENEPA}

La enfermedad VIH lo han traído apách ;como tú! y paisanos que se fueron y trajeron.

(Luisa, madre awajún, 29 años, 2018)

Una mañana, luego de tomar el desayuno con la familia Tuwi, les pregunté si me podían explicar lo que ellos llamaban de «síntoma de sida». Sentados en la mesa, la señora Tania, su esposo, su hija y yo comenzamos a plasmar la silueta de un cuerpo en mi cuaderno de campo. El primer síntoma que resaltó fue la «lombriz en la garganta» y el segundo fue el «hígado duro y caído». Ellos conversaban entre sí (en awajún) y juntos colocábamos las marcas en el dibujo recordando los diferentes casos que se habíamos escuchado en la comunidad. En su comunidad de 1231 personas, distribuidas en 266 casas (INEI, 2017), la mayoría de 
las familias parecía haber vivido de cerca lo que pasaba cuando se decía que una persona tenía VIH/sida.

Los «síntomas del sida» mencionados esa mañana fueron (ver imagen 1): enflaquecimiento, intashi uwegu («caída de cabello»), tseweu («fiebre»), nampichiaanin minitu dekapeu («una lombriz atracada en el cuello»), muun iyaan jegkemjuku wakeg («hinchazón en la barriga», «se siente dura»), wakeenajemamu («dolor de estómago»), kuwin amau («heridas en todo el cuerpo»), achiku numchip («heridas en la garganta y boca»), akape tajaku («el hígado se hincha y baja»), buuk najamu («dolor de cabeza»). Otras familias sumaron a estos síntomas: diarrea, fiebre y alto deseo sexual.

La noción awajún de cuerpo humano constituido por órganos internos parece haberse visto influida de las clases de anatomía que incorporó el Instituto Lingüístico de Verano (ILV) en este territorio. El ILV, desde 1979, se encargó de escribir lecciones de biología con la intención de adaptar la noción de cuerpo como sistema biológico al pensamiento awajún de los escolares. La imagen 2, muestra algunas páginas de este libro enfocado en hacer «mirar [a los awajún] lo que hay dentro» de sus cuerpos. Sin embargo, después de cuarenta años de escolarización, las ideas awajún sobre los órganos internos del cuerpo parecen no ser las que se intentaron enseñar en la escuela. Su forma de pensar los órganos, sistemas vitales y funciones muestran que hay una fuerte influencia del conocimiento apách, pero, a su vez, refleja la existencia de propias perspectivas awajún sobre los sentidos y sensaciones en sus cuerpos que provienen de sus antepasados.

Lo que se conoce como «síntomas del sida» para los awajún está, en consecuencia, conformado por dolores específicos, sensaciones y excreciones que se evalúan a detalle por las familias. Por ejemplo, la memoria de algo en la garganta que impedía engullir los alimentos era una sensación de alerta máxima. La imposibilidad de comer se asociaba directamente al enflaquecimiento, debilidad y pérdida de motricidad en la persona; llevándola velozmente a la muerte.

Como sugiere Langdon (1995), las señales de una dolencia no son por naturaleza claras. «Son ambiguas, causando interpretaciones divergentes entre las personas», incluso aunque las personas compartan concepciones y sistemas de diagnósticos semejantes (p. 9). Los conocimientos, sensaciones, experiencias y relaciones de la persona enferma y de su red serán, por tanto, los cimientos para definir qué los afecta, cómo afrontarlo y qué pasos seguir en la lucha por la vida. 
Figura 1. Signos del "Síntoma de sida" identificados en la comunidad de Kusu Kubaim

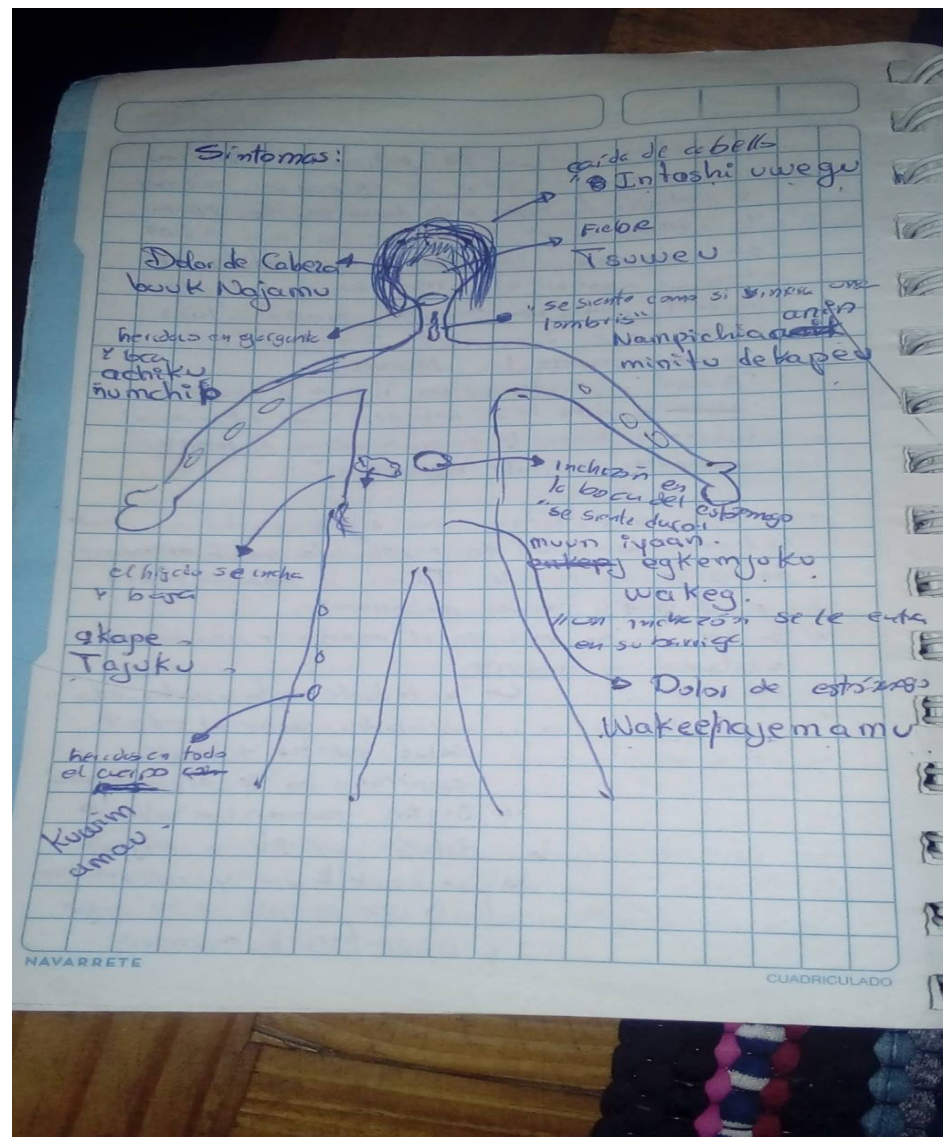

Fuente: Elaboración propia con la familia Tuwi, 2014. (Flores, 2019)

Cuando el «síntoma de sida» se hace presente en una familia inician las sospechas de estar sufriendo una enfermedad (jata sida) o un daño (waweamu «con síntoma de sida»). A continuación, explicaré lo que las familias con quienes trabajé entienden por estas dos nociones. 
Figura 2. «El cuerpo humano», documento de trabajo aents iyashi (ILV, 1979).

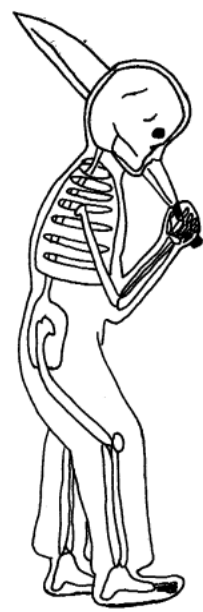

Yamai wainmainitkuín dimainitji iyashum initken ukunch distasa iyashnumia.

«Ahora, si pudiéramos mirar lo que hay dentro de usted, podríamos ver los huesos de su cuerpo» (p. 17)

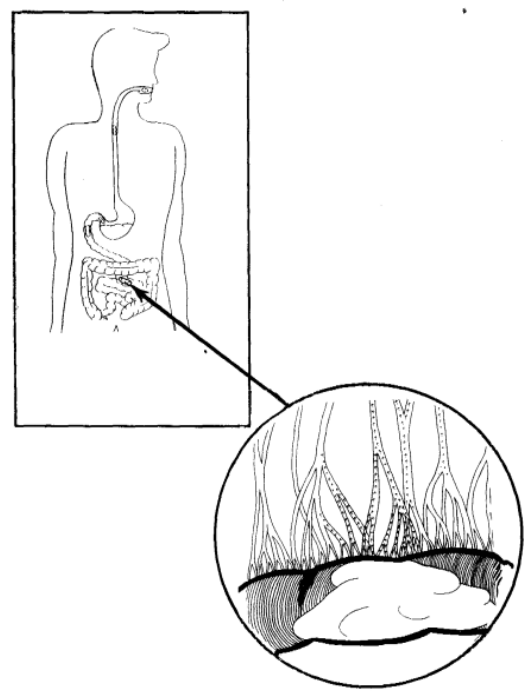

«¿Puede ver todos esos pequeños tubos dentro de sus intestinos? Esos tubos son los vasos capilares. Estos vasos capilares recogen el alimento, de aquí el alimento pasa a la sangre. Esta corre y pasa por todas las partes del cuerpo» (pp. 20-21)

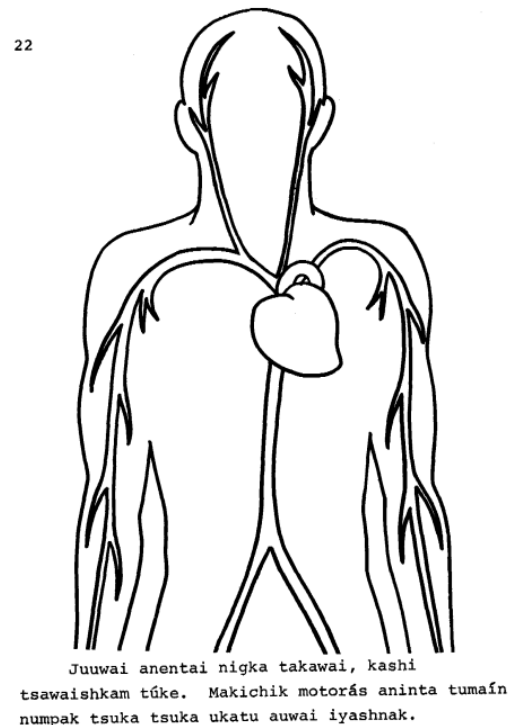

«Ahora, aquí está su corazón. Su corazón trabaja noche y día. Es como un motor que hace que la sangre vaya por todo el cuerpo» (p. 18)

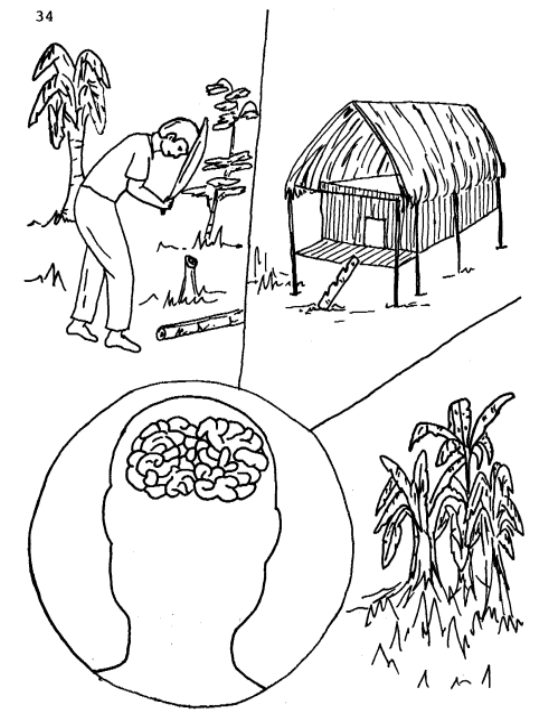

«Su cerebro le enseña a cultivar la chacra para que su cuerpo pueda tener alimentos. Su cerebro le enseña a usar el machete. Con su cerebro usted ha aprendido a construir una casa para proteger su cuerpo de la lluvia, del frío y del calor» (p. 34) 


\section{«Jata sida»}

Cuando una persona presentaba los «síntomas de sida» descritos previamente, esta, a veces en compañía de algún pariente, iba al puesto de salud para hacerse una prueba rápida de sangre. «Eso que te sacan sangre» decían algunos jóvenes y que otras familias también llamaban «hacerse la prueba». Los puestos de salud del distrito de El Cenepa incentivaban esta práctica en las comunidades. Por ejemplo, el puesto de salud de la comunidad de Kusu Kubaim tenía pintado en su fachada el siguiente mensaje «Wejajai numpa jikmi ishamtusuk» o « ¡Vamos a sacar sangre sin miedo!».

\section{Figura 3. Mural del puesto de salud Kusu Kubaim, distrito de El Cenepa}

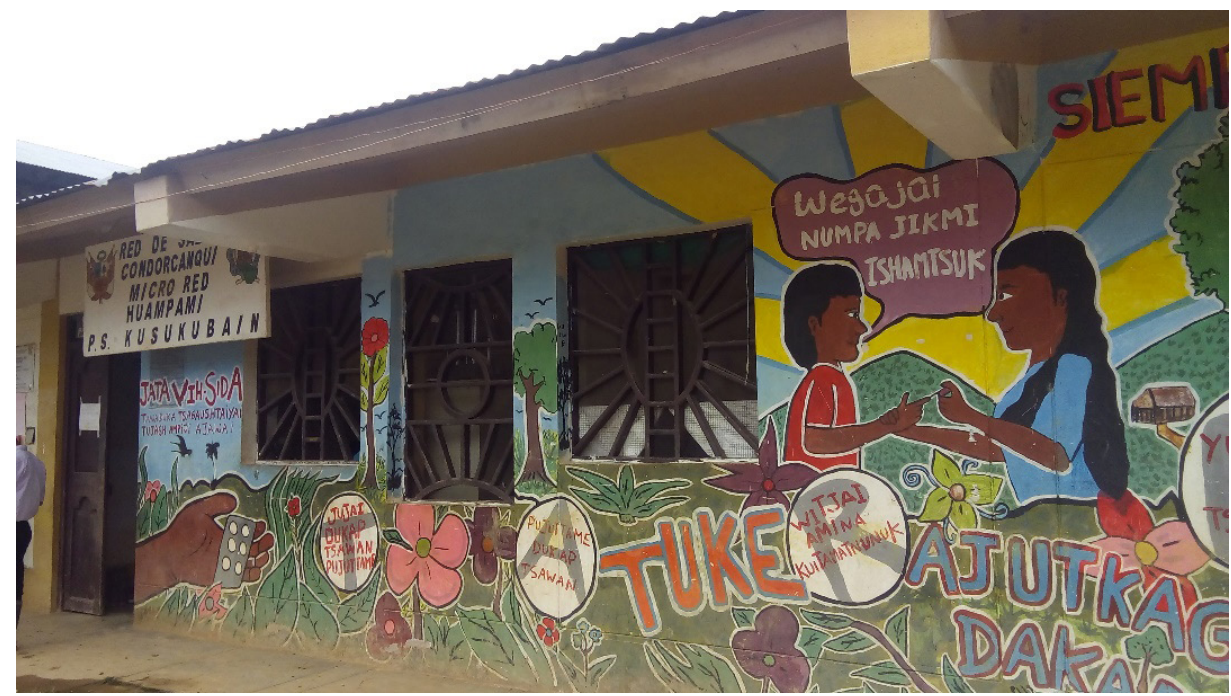

Fuente: Archivo personal Ximena Flores, 2018.

La prueba rápida de sangre demoraba apenas veinte minutos, al cabo de los cuales el personal de salud encargado informaba al paciente su resultado. Si este era reactivo (es decir que se encontraron anticuerpos de VIH en la sangre de la persona), el personal de salud realizaba una segunda prueba rápida (de otra marca comercial). Si esta nueva prueba era reactiva, se informaba al paciente la necesidad de tomar otra muestra de sangre, ahora de la vena, para realizar la prueba ELISA ${ }^{1}$

\footnotetext{
1 Ensayo por inmunoabsorción ligado a enzimas (ELISA), es una prueba de laboratorio que identifica la presencia de anticuerpos contra el VIH (Minsa, 2018).
} 
y así confirmar el diagnóstico de VIH. Algunas personas awajún recordaron que se les hizo firmar un permiso para que sus muestra de sangre sean llevadas a un laboratorio en Lima. Según el personal de salud, los resultados confirmatorios de la prueba ELISA demoran entre dos y tres meses en llegar del Instituto Nacional de Salud al distrito de El Cenepa. Los awajún se mantenían a la espera de esta confirmación que en algunos casos nunca llegó.

A mi hijo en el colegio le dicen que tiene enfermedad de VIH. Ahí, [el personal de salud] lo llevó a Nieva y dijo que iban a traer su resultado, pero nunca le dieron (Lucía, madre awajún, 46 años, 2018)

Tantas veces pienso. A mi hijo le sacaron sangre seis veces. ¡Ha muerto mi hijo y nada! No hemos sabido ese resultado. ¡Sin avisarnos nos llevan la sangre, lo mandan no sabemos a dónde! No nos dicen cuánto tiempo para esperar [el resultado] ¡Ellos no nos avisan! (Tania, madre awajún, 54 años, 2018)

Según el personal de salud, luego de tomar las muestras de sangre, ellos explicaban al paciente qué era el VIH y cómo se trataba. En estas consultas inmediatamente se recomendaba el consumo de esquemas antirretrovirales (TARGA). Sin embargo, la falta de un diagnóstico claro causó desconfianza en las familias awajún que comenzaron a temer por la muerte continua de sus jóvenes.

«Estamos muriendo como pollos», «dijeron que mueran como pollos», «una enfermedad que los mataría como pollos», eran las expresiones con las que los awajún comentaban su percepción de la epidemia. «Morir como pollos» era una analogía del $\mathrm{VIH} /$ sida con la peste que diezmaban a todos los animales en la comunidad. Para los abuelos, el VIH/Sida similar a la peste de pollos se propagó rápidamente en las comunidades debido al intercambio de fluidos; en especial por la multiplicación de los contactos sexuales. «Van a morir así. Porque mucha gente hace muchas relaciones por aquí y allá. Por eso exactamente llegó [la enfermedad]» (muun José).

La idea de que el jata sida estaba relacionado con una mayor incidencia de prácticas sexuales era algo común. Especialmente se asociaba al incremento de las prácticas sexuales de los jóvenes en edad escolar; en prácticas de sexo transaccional y homoeróticas. Los abuelos awajún criticaban este incremento de las prácticas sexuales, pues las percibían como lejanas a sus prácticas de resguardo y búsqueda de visión. Para el muun Nankay, de 82 años, la debilidad de los nuevos cuerpos awajún se asociaba a este inicio sexual temprano. 
Antes nuestros padres nos contaban que no se puede caminar detrás de las mujeres ¡Es peligroso! Temprana edad no se podía tener relaciones, ¡se revienta la cabeza! Antes los papás aconsejaban: «No junten con las mujeres, ¡Su olor es fuerte! Cuando se huele, los hombres sin visión tienen vida corta».

Esta percepción de los peligros del sexo ha generado la estigmatización de las personas que viven con VIH en el distrito de El Cenepa. Muchos awajún consideraban que esta condición se debía a la falta de cuidado de la persona sobre su cuerpo. Recibí esta respuesta de forma constante en conversaciones con estudiantes (varones y mujeres) de entre catorce y diecinueve años. Ellos decían que la «culpa» era de las personas que «no controlaban su cuerpo»o «no se cuidaron a sí mismas» porque mantuvieron relaciones sexuales con múltiples parejas, incluso sabiendo que tenían jata sida. El escrutinio sobre el número de parejas sexuales, las acusaciones de irresponsabilidad y la asociación entre el $\mathrm{VIH} /$ sida con la muerte hicieron que el diagnóstico de VIH sea emocionalmente devastador en las comunidades.

La vergüenza era, por tanto, un sentimiento que las personas que vivían con VIH mencionaban frecuentemente y que, en algunos casos, llevó a muchos a callar sus diagnósticos. Como me comentó un muchacho de 16 años: «no puedo contar sino mis familiares podrían conocer como soy yo». Sin embargo, en la mayoría de los casos, los afectados terminaban compartiendo sus resultados con sus progenitores, quienes se convertían en sus principales cuidadores. Ellos servían de respaldo afectivo y psíquico para los hijos e hijas jóvenes, porque existía el temor que la persona diagnosticada con VIH se pueda «alocar»" ${ }^{2}$ En palabras awajún, el hijo enfermo o sus hermanos podían sufrir tanto al «pensar y pensar» en la enfermedad que «solitos se volvían como enfermos», dejaban de ver la realidad y actuaban sin razón, como si ya no tuvieran razón en el corazón (anentáinchau).

Por ejemplo, supe el caso de Gabriela, una muchacha awajún de diecinueve años que luego de la muerte de su hermano «pensó, pensó y [de tanto pensar] se enfermó»». Su madre, la señora Juana, me contó que la misma condición había afectado a su hijo en el año 2017, cuando supo su diagnóstico de VIH en el puesto de salud. «De un día para otro», de tanto «pensar y pensar», su hijo «dejó de hablar, de comer, enflaqueció y murió». El diagnóstico de positivo o «código»,

La OPS (2010, p. 57) en un estudio con jóvenes y adolescentes indígenas de Bolivia, Ecuador, Guatemala, Nicaragua y Perú, identificó que la vergüenza luego del diagnóstico de VIH afecta el estado emocional de los jóvenes, llevando en algunos casos a la depresión y a la muerte. 
una jerga médica que se escuchaba entre las familias, lo había llevado a acelerar su enfermedad: «peor estaba pensando y se volvió como enfermo».

Durante mi trabajo de campo, Gabriela no mejoró de esta condición de «alocamiento». Ella permanecía encerrada en cuarto porque no aceptaba usar ropa, se ponía violenta y hablaba en lenguas ajenas que su familia identificaba como balbuceos en inglés. Según su madre, Gabriela era víctima de brujería al igual que su otro hijo. Los dardos de daño atravesaron el cuerpo de Gabriela y le hicieron perder su vida social, como sí «empezara a no vivir» aun estando en vida.

Frente a ello, los madres y padres awajún exigían al personal de salud ser informados sobre los diagnósticos de sus parientes y los tratamientos que ellos deberían usar. Las familias awajún, replicando los mensajes difundidos por el personal de salud, recalcaban que el VIH/sida era una enfermedad «con la que se puede vivir» por muchos años a condición de seguir un tratamiento, llamado en awajún ampi o ampi jata sida. Sin embargo, los efectos adversos que reportaron las personas seropositivas aumentaron la desconfianza hacia los antirretrovirales.

«El cuerpo queda mal», era la queja que algunos jóvenes. El consumo diario de «una pastilla rosada y una pastilla azul» (en referencia los esquemas de Zidovudina, Entricitabina, Efavirenz o Tenoforvir), en muchos casos, les había causado mareos, cansancio, delgadez, brotes de heridas en la piel, alergias o sueños de persecución, incluso a personas que antes del tamizaje eran asintomáticas. Estas pastillas «enfermaban» incluso a las personas asintomáticas, era la queja de algunas familias.

En Puesto de Salud, los doctores llamaron a todo los jóvenes y señoritas, y ahí sacaron su sangre. ¡Con trece años a mi hijo le dijeron que tenía VIH y le dieron dos pastillas [antirretrovirales]! Una celeste y otra rosada. Tomó cuatro días, y sentía que se empeoraba más. ¡Antes no tenía nada! Comenzó a tomar y se sentía más débil, se mareó y se desmayó. Él mismo sentía que le caía mal, se complicaba. La piel se le llenó como de heridas rojas, con dolor de estómago y vómito. ¡Estaba bien débil! Ahí lo dejó (Alberto, padre awajún, 40 años, 2018).

A mi hermano de catorce años le habían dicho en el puesto de salud que tenía jata sida. Él vivía en otra comunidad donde estaba el colegio. Le dijeron que le podían dar medicina [antirretrovirales]. Le dieron y se puso ¡totalmente mal! Le dolió el estómago, le vino fiebre de 40 grados. Esa pastilla le dieron antes de que sepa mi papá y mi mamá. Él estaba en segundo, tercer año y le dieron así no más ese tratamiento ampi jata sida. 
Así, a un pata del colegio lo mataron: sin que sus padres sepan le dieron medicina y así murieron alumnos. ¡Si empeora entonces no es VIH! Que se empeore con pastillas, eso dudo (especialista en plantas awajún, 22 años, 2018).

El tratamiento antirretroviral generó, como se muestra, problemas y resistencias en la población awajún, pues al ser una pastilla que «debilitaba» fue vista como ineficiente. Por ello, la decisión de tomar o no antirretrovirales se afrontó diariamente. La incapacidad de realizar actividades diarias y los continuos malestares que su consumo causaba no se condecía con la percepción awajún de salud.

Luego de un análisis detallado de los efectos físicos, sensoriales y oníricos las familias, muchas veces, decidían abandonar temporalmente el tratamiento o complementarlo con otras plantas y preparados. Sin embargo, cuando los síntomas no mejoraban. las sospechas de daño se hacían más fuertes.

Se te da medicina, medicina, y no se mejora. Sigue enflaqueciendo, enflaqueciendo y ya bien flaquito se muere. Nuestras familias dicen que es waweamu. No es de enfermedad de VIH. Es algo que están jugando (especialista sanitario awajún, 35 años, 2018).

Como esta cita mostró, el rápido deterioro o la muerte de una persona diagnosticada con VIH o sida por el puesto de salud generaba sospechas de waweamu o daño en la familia.

Aquí no se puede saber si hay jata sida. Algunos doctores comentan que una persona con enfermedad de VIH no puede morir rápido, tiene que pasar síntomas. Ahora los jóvenes se enferman y mueren en de una semana. Así gordos, su cuerpo se mancha y se muere. Nos dicen que pueden vivir muchos años, pero aquí, en dos semanas no más se mueren (Carlos, padre awajún, 60 años, 2018).

Por ejemplo, hoy día te enteras de que tienes enfermedad de VIH y dentro de un mes te mueres. ¿Eso, qué es? Es por eso por lo que los muun tienen muchas dudas. Ahora ya odiamos ir al puesto de salud porque te dicen que tienes y ahí no más te enfermas (Tulio y María, esposos awajún, 70 años, 2018).

Detectan hoy día y ya comienza a sentir síntomas: fiebre, ronchas, le duele la cabeza, tiene diarrea, y en par de meses esa persona ya está muerta. ¡Por eso creen que es waweamu!, porque los especialistas explican que la enfermedad de VIH no puede avanzar tanto (técnico sanitario awajún, 67 años, 2018). 
En este contexto de desconfianza, existen muchas dudas en torno a la legitimidad del puesto de salud y de su personal. A veces, en lugar de ser vistos como un lugar de salud, es visto como un espacio peligroso donde los tunchis (brujos) «juegan» a mandar dardos y enfermar más a las personas.

\section{«Waweamu con síntoma de sida»}

Durante mi estadía en el distrito de El Cenepa pude percibir que todo awajún decía ser vulnerable de ser afectado por la existencia de «dañinos», «mágicos» o, también llamados, tunchis $^{3}$ que vivían en sus comunidades. Antiguamente, como recuerdan los abuelos, los tunchis se formaban respetando los rituales de toma de ayahuasca (Banisteriopsis caapi), llamadas en awajún yagé tunchimuo. Este ritual de iniciación se hacía bajo la guía de otros tunchis y por medio de la alianza con los $i$ wanch ${ }^{4}$ o «los espíritus de los muertos». Los aprendices eran sometidos a una serie de pruebas que debían superar para «tener el espíritu del mundo» ${ }^{5}$ y poseer los dardos tséntsak $k^{6}$ de daño.

En el pasado, los tunchis no eran unívocamente malos: también eran grandes curanderos. Sin embargo, con la llegada de las misiones, los iwanch fueron asociados al demonio y los tunchi fueron clasificados como «malévolos» (Priest, 1993; Riol, 2015). Además, diversas prácticas de magia de origen europeo fueron introducidas en la región y atribuidas a los tunchis awajún. Las familias awajún de las comunidades que visité denunciaban que estos nuevos tunchis se formaban con la lectura de libros de magia negra, cartomancia y magia blanca, que llamaban de iwanch papi o "papeles del diablo». Estos estaban escritos en castellano y podían ser descargados de internet o comprados a los comerciantes apách que ingresaban a sus comunidades. El aprendiz de tunchi con estos libros iniciaba un lento proceso, llamado por los awajún como de «invocar poderes». Iba al cementerio de noche, rezaba y llamaba a los muertos para el cumplimiento de pruebas.

3 El poder de los tunchis está asociado a Tsugki, el primer chamán mitológico que vive en el fondo de las aguas (Delgado, 1986, p. 13).

4 «Antropoides de color sombrío en los que se materializa el alma de los muertos. Les gusta asustar a las mujeres y los niños que raptan, también se divierten haciendo caer objetos» (Descola, 2005, p. 319).

5 Rubén, profesor awajún, 48 años, 2018.

6 Según Brown (1984, p. 16), luego de obtener los tséntsak, «el brujo se traga los dardos y los lleva en su garganta, pecho, brazos y manos. Luego de un largo periodo de ayuno y consumo de tabaco, podrá controlar sus dardos». 
Las familias incómodas afirmaban que estos nuevos tunchis «juegan a hacer daño» por medio de los dardos tséntsak. Así lo explicó Liz, una joven awajún de veintiún años: «El daño entra como flecha [al cuerpo], eso es tséntsak. Espiritualmente, a través de tséntsak se daña a la gente». Estos dardos guardados en la boca de los tunchis se alojan en los pliegues físicos y espirituales de cuerpo de sus enemigos y pueden causarles la muerte.

« ¡Todo aquí es brujería!», era una expresión que se escuchaba cotidianamente en las comunidades awajún donde trabajé. Si alguien se ahogaba nadando en el río, sí una canoa se volteaba, si alguien enfermaba gravemente o si alguien moría, las sospechas de brujería despertaban. Lo notable de esta dinámica de sospechas era que, al no saber quién hizo la brujería, las relaciones con otras familias se volvían potencialmente peligrosas. "El tunchi brujea. Cuando tú discutes con alguien o su familia, el tunchi pone enfermedad. Comienza a poner fiebre y así empieza. ¡Nunca te salvas!», se quejaba un señor awajún de 63 años.

Las relaciones entre familias son, en consecuencia, una urdiembre tensa que puede quebrarse rápidamente. Carla, una docente awajún, recordaba esta guerra invisible de dardos tséntsak que se disparan de una casa a otra como un espectáculo invisible de flechas en el cielo que ella vio cuando tomó ayahuasca (Banisteriopsis caapi). Durante su visión, en una casa frente al río, lejos de su comunidad, ella vio las líneas en el cielo de los disparos de dardos que las casas se mandaban mutuamente. Ella decía: «El cielo estaba lleno de luces. Es una guerra de flechas que va de un lado a otro. Entre casas se van mandando [los dardos]. ¡Una guerra es!».

Las personas, por ello, estaban atentas a cualquier señal que les revelase que habían sido víctimas de daño: un malestar después de jugar fútbol, ver un búho camino a casa, soñar con un murciélago, haber sido preguntado por la salud de un familiar que luego cae enfermo, la entrada de una rata que se abrió camino a la cama atravesando el mosquitero, escuchar al pásug (ave de malagüero), vomitar insectos, arena o cabellos, entre otros signos. Estas señales se percibían como avisos que eran recordados a detalle cuando sucedía una enfermedad o un accidente. Frente a estos eventos, las personas se juntaban entre parientes y recordaban colectivamente estos episodios para intentar reconstruir los posibles eventos del daño y para descubrir quién fue el responsable de esa afrenta.

Según las familias awajún, el deseo del tunchi de hacer daño se debía a rencillas latentes entre familias (por infidelidad, bigamia, territorios en disputa, 
entre otros) o por la envidia que este personaje tenía por los logros o bienes de otras personas. «Envidia es muerte», decía un especialista sanitario awajún de 80 años: los tunchis «ponen daño para que no tenga dinero, para que sea mi obrero, que venga [el dinero] para mí». La palabra envidia en castellano o kajinayam en awajún se usaba cuando una persona deseaba lo que otra persona tenía. Se «mezquinaba» —en términos awajún - la prosperidad del vecino, haciéndole daño para evitar su éxito. «El vecino desea lo que uno tiene y por eso manda el daño», me explicaba una madre awajún. Frente a ello, los awajún decían cuidarse de los lugares por donde caminaban y de las relaciones que entablaban.

La proliferación sin precedentes de tunchis en el distrito de El Cenepa asustaba a los padres awajún, y por ello, preferían que sus hijos e hijas más jóvenes estén en las ciudades. Sin embargo, esta era, a su vez, una seguridad ambigua, porque las ciudades presentaban también otros peligros. Según decían, en las ciudades había otros tunchis (awajún y apách) y muchas enfermedades que afectaban a los jóvenes que migraban. Cuando los jóvenes terminaban sus estudios o tenían éxito en algún negocio, se volvían el objeto de envidia de los demás, y cuando regresaban a sus comunidades eran más vulnerables a ser víctimas de brujería.

Así, por ejemplo, muchas familias awajún comentaban cómo sus hijos comenzaron a enfermar luego de estudiar, de salir a la ciudad, de ganar dinero y de hablar castellano. «Hay mucha envidia aquí», decían los jóvenes y sus progenitores, que, en algunos casos, preferían no volver a sus comunidades. Pareciera que los aspectos que daban cercanía al modo de ser apách (haber estudiado, hablar castellano o tener un trabajo asalariado) eran aspectos asociados con el «progreso», y por ello eran objeto de envidia: «Ahora dicen que síntoma de sida sale de la boca de un brujo. ¡Jóvenes que son estudiantes, ellos mueren!» (Sonia, madre awajún, 56 años, 2018)

La envidia tenía muchos pliegues y desdoblamientos en el caso awajún: no era una situación simplemente ambigua, sino con múltiples ambigüedades. Los awajún se sentían amenazados en las comunidades donde había muchos tunchis awajún; también percibían amenazas en las ciudades, donde corrían el peligro de ser afectados por tunchis apách y awajún, y si decidían volver a las comunidades, también se sentían particularmente vulnerables por la envidia que puede generar el haber estado en las ciudades. « No quieren que los indígenas mejoren!», era la queja final de una madre awajún.

En este contexto de peligros, la actualización del repertorio de los tunchis fue inevitable. Como argumenta Pérez-Gil (2001) los sistemas chamánicos de los pueblos amazónicos son representaciones colectivas y sus especialistas poseen una capacidad creativa que se actualiza. Por ello, con la llegada de las enferme- 
dades apách, se generaron también nuevas formas de hacer daño. Ese fue el caso del «daño con síntoma de sida»: «Aquí los mágicos han aprendido malas cosas. [Los tunchis] mandan que mueran con síntoma de sida» (María, madre awajún, 66 años, 2018).

Según la población awajún, los tunchis tenían la capacidad de:

1) Crear tséntsak o dardos de VIH y de sida y mandarlos a sus enemigos.

2) Causar falsos positivos en el puesto de salud, es decir, hacer que en el diagnóstico de sangre aparezca un resultado positivo cuando realmente la persona no tenía jata sida sino «daño con síntoma de sida».

3) Empeorar la condición de personas que han sido diagnosticadas con jata sida; es decir, aunque las personas usen los antirretrovirales e intente curarse con otros métodos awajún, no mejora.

El tunchi atraviesa las casas, los puestos de salud y el cuerpo de su víctima con los dardos de daño con «síntomas de sida» que se alojan en el espíritu, los órganos, las extremidades, e incluso las casas de las personas. Lo que para el punto de vista biomédico es una epidemia causada por el virus, desde el punto de vista awajún es un descontrol de actividades de brujería entre personas awajún. Una percepción similar fue asociada a otras epidemias introducidas en el pasado por población apách, como el sarampión?.

Las familias con quienes conversé tenían la percepción de estar siendo afectadas deliberadamente por fuerzas que «aprovechaban» su condición de fragilidad. «De la brujería [uno] no se cura, pero de la enfermedad sí» ${ }^{8}$, era la distinción clara para saberse dañado.

Aprovechando que es VIH, así no más mueres. Eso le dijo el brujo a mi hijo. Primerito fue al puesto y le dijeron que es VIH, lo inyectaban, pero no se cortaba. El brujo le dijo que no era enfermedad de sida sino que era waweamu [brujería] (Miguel, señor awajún, 50 años, 2018).

El brujo se aprovecha. Escucha que tiene VIH y ahí no más dice para que [esa persona] muera (Clara, joven awajún, 20 años, 2018).

Este año están estudiando mucha magia. No calma nada con ese remedio [antirretrovirales]. Llevan al curandero y ahi saben que no es enfermedad, es sida, que le han puesto los mágicos. Por eso nosotros decimos: «No sanan por

7 «Dos iwishín decidieron vengar la muerte de un familiar colocando tsag («tabaco») con "síntoma de sarampión" en el suelo de las casas. El resultado fueron tres muertos» (Lazo, 2014, p. 19).

8 Ruben, profesor awajún, 48 años, 2018. 
remedio, los están engañando». Algunos sí se recuperan por remedio, otros no (especialista de plantas awajún, 22 años, 2018).

Si fuera enfermedad de VIH, ¿por qué se presenta una persona fastidiándome en mis sueños? Yo nunca voy a ir al puesto de salud. ¡Yo tengo waweamu! (joven seropositivo awajún, 17, 2018).

El personal awajún de los puestos de salud también reconocía la existencia del daño como explicación a algunos eventos médicos inexplicables. Más de uno decía sorprendido que, durante sus años de trabajo en los puestos de salud públicos, se habían topado con casos que solo se pudieron resolver con la ayuda de plantas o de otros especialistas no biomédicos. Por ello, un técnico sanitario awajún, de 35 años, consideraba necesario que los padres explicaran a los jóvenes que: «iSí hay brujos! Eso es cierto. Pero también tenemos enfermedad de VIH/ sida y deben usar también condón».

La sospecha de haber sido dañado implica a las familias afectadas la búsqueda de curas chamánicas. Muchas veces, primero se recurre a las plantas maestras (toé y ayahuasca) para confirmar el daño y, en caso de gravedad, las familias pueden decidir ir donde un tunchi que saque del cuerpo del enfermo los tséntsak de daño.

\section{TORNARSE ENEMIGO: DAÑOS COLATERALES DEL «DAÑO CON SÍNTOMA DE SIDA»}

Antiguamente, cada vez que una persona moría, se convocaba a una reunión comunal de «acusación de daño». El día indicado, el jefe de la comunidad actuaba como árbitro entre las familias que se acusaban en público. Usualmente, la familia de la persona que se consideraba víctima de brujería iniciaba la narración de su caso. En esta narración, los parientes del enfermo contaban las visiones, visitas, sueños y diagnósticos que su pariente experimentó durante el tiempo de la enfermedad. Sobre la base de esas pruebas se podía denunciar públicamente a alguien de ser tunchi. Luego de la explicación de la familia afectada, se escuchaba la versión del «sospechoso de tunchi» o de su familia. Ellos normalmente negaban todo y decían que existía otro tunchi con tanto poder que había utilizado la imagen del acusado para presentarse en los sueños de sus víctimas. La expectativa de los denunciantes, típicamente, era expulsar al acusado de la comunidad. Una vez decidida esta sentencia, el destierro del tunchi era inmediato. De no cumplirse este acuerdo, el sospechoso podía ser asesinado, porque significaba un peligro para las familias de su comunidad. 
Actualmente hay menos reuniones de este tipo, pero todavía es muy importante para las familias hablar de los sueños o visiones de persecución que tienen los enfermos. Se considera que los tunchis se hacen visibles a sus víctimas oníricamente o durante la toma de plantas maestras (toé y ayahuasca). En estos momentos el tunchi muestra su verdadero rostro al «molestar» a la persona enferma. Por ello, cuando una persona sueña con un sospechoso de brujo o ve que este la ataca durante su visión de cura, se considera que es una prueba irrefutable de haber sido dañado.

En 2014, el temor de estar siendo nuevamente afectados por un tunchi llevó al asesinato de un acusado en una comunidad del distrito de El Cenepa. La población comentaba que, luego de ser encontrado culpable por la muerte de jóvenes con «síntomas de sida», el acusado se resistió a salir de la comunidad y un waimaku (persona con visión larga y guerrera) de otra comunidad lo siguió a su chacra y lo mató con un disparo de escopeta. Actualmente, muchas familias aún adjudican el surgimiento de sus primeros «síntomas de sida» a este tunchi.

Según un profesor apách del distrito de El Cenepa, en el actual contexto de VIH no es difícil ser sospechado de tunchi: «Si le hablaste y se cayó luego de verte, ¡ahí te sospechan! A mí me pasó». El profesor recordó que cuando vivía en otra comunidad, su hija de catorce años se había enamorado de un joven awajún de diecisiete. Por rumores de otras familias, supo que el muchacho había presionado a su hija para tener relaciones sexuales. Toda su comunidad comentaba que ese joven tenía «sida». Indignado, él agarró un palo de escoba, buscó al muchacho y lo golpeó en la espalda. La familia del muchacho dijo que, después del golpe, el joven se puso débil y enfermó. «Le pegué con palo y comenzaron a decir que le puse daño de sida en el palo», contaba el profesor. Luego de esa acusación, en la comunidad dijeron que él era tunchi, y por miedo a las represalias, huyó con su familia. En la nueva comunidad, donde reside actualmente, sus vecinos sabían el motivo por el cual ellos huyeron. Las otras familias comentaban que hasta ahora él no había hecho nada y por eso no lo expulsaban, pero estaban alertas ante cualquier indicio. Por ello, el profesor y su esposa preferían no interactuar mucho con el resto de la comunidad.

Los cultos evangélicos han tenido una fuerte influencia en este proceso de ajusticiamiento a los tunchis. La criminalización de estas acusaciones mantiene las rencillas familiares encubiertas. Las personas que participan en los cultos evangélicos tienen miedo de acusar públicamente a un supuesto tunchi por los nuevos temores de «pecado» y de «no ir al cielo» que el evangelismo inculca en la población. Especialmente, las familias que participan de la Iglesia del Nazareno temen que cuando se acusa en las reuniones comunitarias a alguien de ser tunchi 
se compromete el destino del alma de la persona que fue (supuestamente) víctima de brujería. Acusar a un tunchi es la prueba de que uno cree en los tunchis, y por ello el alma del pariente muerto no irá al cielo.

Sin embargo, el temor de acusar públicamente no hace que la brujería deje de ser central en la explicación de muertes, enfermedades y accidentes awajún. Las familias, aunque no denuncien al sospechoso de tunchi en una reunión comunal, comentan de sus sospechas de brujería en los espacios cotidianos, cuando se están bañando en el río o cuando están tomando masato en las fiestas. Todos conversan entre sí contando quién es el culpable de matar a sus hijos. «¡Augusto es tunchi! Dicen que mato a André. También José lo ha visto. La familia de María también lo acusa». Estas son expresiones que escuché de manera recurrente durante el trabajo de campo.

Con el aumento de casos seropositivos en las comunidades, el rápido deterioro de los cuerpos y los efectos adversos a los antirretrovirales, las acusaciones de brujería asociadas al VIH/sida siguen en aumento. Las relaciones entre las familias se mantienen tensas y las conversaciones en torno a la muerte de alguien se ven llenas de denuncias.

\section{PALABRAS FINALES}

Según Giddens (2000, p. 169), la medicina «moderna» promovió a la enfermedad como una condición asociada a tratamientos físicos y explicaciones fácticas. La curación, en estas esferas positivistas, se da mediante la medicina que se desarrollaba desde los sistemas sanitarios. Pero ¿qué otras camadas existen fuera de estas nociones de enfermedad asociada al cuerpo biológico?

A través de la etnografía, el objetivo de este artículo ha sido presentar las nociones awajún sobre el VIH/sida. Los testimonios aquí presentados destacaron la centralidad del cuerpo awajún para entender los procesos de salud y de enfermedad asociados a esta condición. El cuerpo awajún, conformado por el iyásh y el wakán, se hace fuerte por medio de los procesos de formación continua de los parientes. «El cuerpo es resultado de la acción de otras personas, alimentos y plantas que lo moldea y transforman tanto ritual como cotidianamente» (Belaunde, 2003, p. 138). Sin embargo, con la llegada de las enfermedades apách, estos procesos se vieron amenazados. Las familias que tuvieron que actualizar sus procesos de formación de persona y mecanismos terapéuticos para lograr sobrevivir.

Los especialistas awajún biomédicos y no biomédicos, han aprendido a responder a las nuevas afecciones. El cuerpo awajún, conformado por dimensiones 
sensibles y materiales, ha sabido responder a las enfermedades no indígena por medio de tratamientos únicos con medicamentos, plantas y seres aliados. Sin embargo, así como han aprendido a tratarse de las enfermedades apách, la relación con seres suprasensibles ha permitido que, los tunchis o brujos sepan también causar estas nuevas enfermedades. Por tanto, contrario a lo que se suele pensar, la enfermedad y el daño, son experiencias que se superponen continuamente en las familias awajún.

Para las personas awajún con las que trabajé, las sospechas de tener la «enfermedad de sida» (enfermedad sexual que se diagnostica en el puesto de salud y que requiere la toma de antirretrovirales) o el «daño con síntoma de sida» (brujería asociada a los dardos de daño tséntsak que manda deliberadamente el tunchi) se superponían constantemente. La separación clara entre ambas experiencias no era lo central, sino la búsqueda de cura. Para entender mejor esto, presento brevemente el caso de Mateo que fue narrado por su madre, la señora Úrsula:

A mi hijo en el colegio le dicen que tiene enfermedad de VIH. Ahí, [el personal de salud] lo llevó a Nieva y dijo que iban a traer su resultado, pero nunca le dieron. Luego de eso, [al retornar a la comunidad] peor estaba mi hijo ¡Pensando, pensando se volvió como enfermo! Antes, él no estaba enfermo, ¡solo con el tamizaje enfermó! En el puesto de salud, le dieron ese tratamiento, ampi jata sida. Pero cuando tomaba se ponía como loco, ¡como enfermo se sentía! Por eso lo dejamos. ¡Mi hijito estaba mal! Se mordía su lengua. Yo llamé a tío Cesar [técnico sanitario awajún]. Él dijo: «iEso no es enfermedad, es tunche [brujería]!»!! Y le dio de tomar ajeng (Zingiber officinale). Ahí salieron cochinos [vómito tierra, pelos].

Para aliviarle, le pedí a Apajui [Dios] y le di toé (Brugmansia Suaveolens). ¡Yo solita lo preparé! Ahí (Mateo) había vomitado así oloroso, feo. El toé le dijo: «iJata atsá! [«no hay enfermedad»]. Te dieron waweamu [daño], ¡te odian! Tu papá está trabajando como aguatero. Entonces el brujo dijo que su papá muera. Pero como no le pudo dar daño a tu papá, ¡dijo que tú te mueras con «síntoma de sida»! '

[Luego de esa visión], el toé le mostró a mi hijo que iba a estudiar, que se iba a curar, que iba a engordar. El toé le dijo: «No tengas miedo vas a curarte». ¡Desde ahí mi hijito se curó! Se fue a Nieva y ahora está estudiando allá. Con la planta se curó. Mi hijo ya no quiere venir acá, porque aquí hay mucha brujería.

Como muestra el caso de Mateo, además del diagnóstico en los puestos de salud, la enfermedad awajún es constantemente diagnosticada en las familias 
mediante la atención detallada a los signos de peligro. El primer tamizaje de VIH hecho en el puesto de salud, seguido por los primeros síntomas y la falla de los medicamentos antirretrovirales, llevó a la señora Úrsula a buscar otros espacios de salud más efectivos. Para ello, la madre recurrió a un especialista sanitario awajún y a la planta del toé. Esta planta, asociada a la búsqueda de visión de los jóvenes awajún (Brown, 1978), es muy apreciada por sus poderes terapéuticos. El toé, en un viaje sensorial, abre el cuerpo del enfermo y le hace ver las substancias que están comprometiendo su salud. Más confiable que un tunchi, la planta, «que nunca miente y que cura todo» ${ }^{9}$, da la seguridad a los enfermos y a sus parientes de que hay una vida luego de ese estado cercano a la muerte. La cura awajún, por tanto, se presenta dentro un campo de posibilidades muy amplio con la presencia de especialistas biomédicos y no biomédicos, humanos y no humanos y la participación clave de espíritus guía. La lectura de señales, los diagnósticos y múltiples tratamientos que aplican las familias frente a una enfermedad son muestras de la agencia vitalista de esta población.

Para los awajún, la medicina occidental y los remedios apách son conocimientos poderosos. Como sugieren Langdon (2014), Buchillet (2004), Kopenawa y Albert (2015) y Kelly (2010), los pueblos indígenas vienen haciendo suyos los conocimientos biomédicos. Lejos de una dicotomía entre la medicina indígena y la medicina biomédica, las familias awajún parecían apostar por la intermedicalidad. «Cada uno hace su medicina», era una frase que continuamente me decían las familias cuando narraban sus historias de enfermedad. Lo que actualmente se entiende por medicina indígena es también parte de esos procesos de incorporación de otros conocimientos.

Esta forma de entender el VIH/sida en el caso awajún, asociado a experiencias de enfermedad y de brujería, ha retado el entendimiento y la respuesta del Estado peruano. Considero que el concepto de «equívoco» de Viveiros e Castro (2004), recuperado por Kelly (2010), es fructífero para entender las múltiples perspectivas que confluyen en la comunicación de nociones como VIH y sida.

Para la mayoría de los trabajadores del sector salud con quienes conversé (en los ámbitos local, regional y nacional) la principal limitación para realizar su labor en el territorio awajún eran las «creencias de brujería». El daño era entendido como parte de la «costumbre»o «cultura» awajún que se asociaba al desconocimiento de lo que «realmente» era el VIH. Por ello, con el objetivo de informar adecuadamente, hubo planes importantes desde el sector salud para

Tania, madre awajún, 54 años, 2018. 
implementar campañas comunicacionales y de tamizaje en todas las comunidades del distrito de El Cenepa. Esos esfuerzos de comunicación, hechos en idioma awajún, fueron bastante apreciados por la población. Para los awajún, el VIH es una condición que existe fuera de sus comunidades y desean conocer cómo ella se desarrolla en los cuerpos apách. Lo que no se percibe desde los esfuerzos del personal de salud es que el VIH/sida que se presenta en las charlas informáticas a través de nociones biomédica e imágenes de un virus, no corresponden del todo a lo que las familias llaman de $\mathrm{VIH} /$ sida dentro de sus comunidades. La referencia a señales oníricas, las sensaciones de los órganos y las sospechas familiares de posibles daños son aspectos centrales que las familias awajún perciben en sus padecimientos de VIH y sida.

Para hacer un puente posible entre ambos esfuerzos de comunicación, es necesario que el sistema de salud se aproxime a las nociones awajún de enfermedad y de daño asociadas al VIH/sida. Tomar en serio la voz indígena, sus experiencias, demandas y nociones pueden llevar a construir políticas de salud que sean realmente interculturales. La construcción de mejores sistemas de salud depende de esta disposición del Gobierno y el personal de salud, de construir junto con la población indígena sus propios mecanismos de prevención, cuidado y atención.

\section{REFERENCIAS}

Agostini, Rafael, Ivia Maksud y Tulio Franco (2018). «Eu tenho que te contar um negócio»: gestão da soropositividade no contexto dos relacionamentos afetivosexuais dos jovens vivendo com HIV. Sexualidad, Salud y Sociedad, 3, 201-223. https://doi.org/10.1590/1984-6487.sess.2018.30.10.a

Albert, Bruce y Gale Goodwin (1997). Saúde Yanomami. Um manual etnolinguistico. Belém: Museu Paraense Emílio Goeldi.

Albert, Bruce y Alcida Rita Ramos (2002). Pacificando o blanco: cosmologias do contato no norte-amazónico. São Paulo: UNESP.

Belaunde, Luisa (2001). Viviendo Bien. Género y fertilidad entre los Airo - Pai de la Amazonía Peruana. Lima: CAAAP.

Belaunde, Luisa (2003). "Yo solita haciendo fuerza": Historias de parto entre los Yine (Piro de la Amazonía Peruana. Amazonía Peruana (pp. 125-145). Tomo XIV. ํำ 28-29.

Belaunde, Luisa (2005). El recuerdo de luna. Género, sangre y memoria entre los pueblos amazónicos. Lima: CAAAP. 
Brown, Michael (1978). From the hero's bones: three aguaruna hallucinogens and their uses. En Richard I. Ford (ed.), The nature and status of ethnobotany (pp. 119136). Anthropological Papers $N^{\circ}$. 67. Ann Arbor, MI: University of Michigan Press.

Brown, Michael (1984). Una paz incierta. Historia y cultura de las comunidades aguarunas frente al impacto de la carretera Marginal. Lima: CAAAP.

Buchillet, Dominique (2004). Sorcery Beliefs. Transmission of Shamanic Knowledge, and Therapeutic Practice among the Desana of the Upper Río Negro, Region, Brazil. En Neil Whitehead y Robin Wright (eds.), Darkness and Secrecy (pp. 109-131). Durham, NC: Duke University Press.

Castro, Diana (2017). La expansión del VIH y sida: percepciones y respuestas sociales en los wayuu de Colombia (tesis doctoral). Universidad de Granada, España.

Chávez, Giannina (2019). Diálogos médicos: la negociación de los modelos explicativos y narrativas sobre el VIH/SIDA entre la población awajún de comunidades intervenidas en la estrategia contra el VIH/SIDA. (Tesis de licenciatura) Pontificia Universidad Católica del Perú.

Delgado, Hugo (1986). Cultura (cosmovisión) y salud entre los aguaruna-awajún. Apuntes de Medicina Tradicional, 60, 1-38.

Descola, Philippe (2005). Las lanzas del crepúsculo. Relatos jíbaros. Alta Amazonía. Buenos Aires: Fondo de Cultura Económica.

Espinosa, Oscar (2009). ¿Salvajes opuestos al progreso?: aproximaciones históricas y antropológicas a las movilizaciones indígenas en la Amazonía peruana. Anthropologica, XXVII(27), 123-168.

Flores, Ximena (2019). Entre játa y waweamu: VIH/sida en las comunidades awajún de la Amazonía peruana. MANA, 25(3), 777-808.

Garra, Simone (2016). Entre la brujería y la ley: los certificados de un iwishin awajún. En Alexandre Surrallés, Oscar Espinosa y David Jabin (eds.), Apus, caciques y presidentes. Estado y política indígena amazónica en los países andinos (pp. 195-214). Lima: IFEA, IWGIA, PUCP.

Giddens, Anthony (2000). Sociología. Madrid: Alianza Editorial.

Gullart, José María (1990). Entre pongo y cordillera. Lima: CAAAP.

Huamán Byelca, Gushiken Alfonso, Benites Carlos, Quiroz Fabiola \& García, Lisset. 2017. Prevención de la transmisión materno-infantil del VIH en gestantes y madres awajún y wampis de la región amazonas en Perú. Revista Peruana de Medicina Experimental y Salud Pública. 34 (4): 627-632

Instituto Lingüístico de Verano (ILV) (1979). AENTSU IYASHI («El cuerpo humano»). Libro $\mathrm{N}^{\circ} 2$ de ciencias naturales. Lima: Vecinos Mundiales. 
Instituto Lingüístico de Verano (ILV) (1996). Diccionario Aguaruna - Castellano, Castellano - Aguaruna. Serie lingüística peruana. Lima: ILV.

Instituto Nacional de Estadística e Informática (INEI) (2018). Censo Nacional 2017: XII de Población, VII de Vivienda y III de Comunidades Indígenas. Lima: Instituto Nacional de Estadística e Informática.

Kelly, José (2010). Os Encontros de Saberes? equívocos entre índios e Estado em torno das políticas de saúde indígena na Venezuela. Ilha, 11(2), 265-302.

Kleinman, Arthur (1978). Concepts and a model for the comparison of medical systems as cultural systems. Social Science and Medicine, 12, 85-93.

Kopenawa, David y Bruce Albert (2015). A queda do céu: palavras de um xamã yanomami. São Paulo: Companhia das Letras.

Langdon, Esther Jean (1995). A doença como experiência: A construção de doença e seu desafio para a prática médica. Palestra. Conferência 30 anos Xingu. Escola Paulista de Medicina. São Paulo. 23/08/95

Langdon, Esther Jean (2001). A doença como experiência: o papel da narrativa na construção sociocultural da doença. Etnográfica, V(2), 241-260.

Langdon, Esther Jean (2014). La negociación de lo oculto: chamanismo, medicina y familia entre los siona del bajo Putumayo. Popayán: Universidad del Cauca.

Lazo, Rodrigo (2014). Informe etnográfico para propuestas de modificatoria a la NTS de VIH y sida para población awajún de Condorcanqui-Amazonas. Documento de trabajo.

Lévi-Strauss, Claude (1986). A Oleira Ciumenta. Trad. Perrone-Moisés. São Paulo: Editora Brasiliense (Mitos em garrafa de Klein; pp. 197-213).

McCallum, Cecilia (1998). O corpo que sabe da epistemologia Kaxinawa para uma antropologia médica das terras baixas sul-americanas. En P. C. Alves y M. C. Rabelo (orgs.), Antropologia da saúde: traçando identidade e explorando fronteiras (pp. 215-245) [online]. Río de Janeiro: Fiocruz y Relume Dumará. Recuperado de http://books.scielo.org/id/by55h/pdf/alves-9788575414040-12. pdf

Medina, Armando (2019). Representaciones sociales sobre sexualidades y VIH en poblaciones awajún provincia de Condorcanqui - Amazonas. (Tesis de doctorado en Humanidades). Universidad Federal Nacional Federico Villareal.

Menéndez, Eduardo (2015). ¿Las enfermedades son solo padecimientos? En Jornada sobre antropologia i pluralisme assistencial. Universitat Rovira i Virgili.

Microrred de Salud Huampami (2018). Distrito El Cenepa: Número de casos de VIH/ sida [cuadro estadístico]. Informe del Área de Estadística. 
Minayo, María Cecilia de Souza (1991). Abordagem antropológica para avaliação de políticas sociais. Revista de Saúde Pública, 25(3), 233-238.

Ministerio de Salud y Fondo de Población de las Naciones Unidas (2009). Una aproximación cualitativa a la prevención del VIH-sida en dos comunidades nativas de Ucayali. Lima: Instituto de Educación y Salud - IES.

Ministerio de Salud (2018). Norma técnica de salud de atención integral del adulto con infección por Virus de la Inmunodeficiencia Humana (VIH). Lima: Minsa.

Orellana, Roberto e Isaac Alva (2012). Social and contextual factors that influence HIV risk behaviors among indigenous MSM in the Peruvian Amazon. Retrovirology, 9, 112.

Orellana, Roberto, Isaac Alva, César Cárcamo y Patricia García (2013). Structural factors that increase HIV/STI vulnerability among indigenous people in the Peruvian amazon. Health, 23(9), 1240-1250.

Organización Panamericana de la Salud (2010). Salud sexual y reproductiva y VIH de los jóvenes y adolescentes indígenas de Bolivia, Ecuador, Guatemala, Nicaragua y Perú. Washington: OPS.

Ormaeche, M., A. Whittembury, M. Pun y L. Suárez-Ognio (2012). Hepatitis B virus, syphilis, and HIV seroprevalence in pregnant women and their male partners from six indigenous populations of the Peruvian Amazon Basin, 2007-2008. International Journal of Infectious Diseases, 16, 724-730.

Pérez-Gil, Laura (2001). O sistema médico Yawanáwa e seus especialistas: cura, poder e iniciação xamânicas. Caderno de Saúde Pública, 17(2), 333-344.

Pina de Barros, Edir (2000). El sida: representaciones indígenas y políticas sociales. Gazeta de Antropología, 16. Artículo 03.

Pintado, Isaías (2016). La implementación de políticas públicas en salud para los pueblos indígenas de Santa María de Nieva en Amazonas: la tensión entre la atención al VIH-sida y el enfoque intercultural (tesis de maestría en Ciencia Política y Género). Pontificia Universidad Católica del Perú.

Portocarrero, Julio (2015). VIH en gestantes indígenas: un reto para la salud pública peruana. Revista Peruana de Medicina Experimental y Salud Pública, 32(3), 546-554.

Priest, Robert (1993). Defilement, moral purity, and transgressive power. Their symbolism of filth in Aguaruna Jivaro culture. Berkeley, CA: University of California.

Red de Salud Condorcanqui (2018). Reporte de casos de VIH entre 2010 -2018. [Base de datos]. Informe del Área de Estadística. 
Riol, Raúl (2015). La construcción del Cenepa como lugar indígena. Una historia awajún y wampis de relación y defensa del territorio (tesis de doctorado). Universidad Autónoma de Madrid.

Santander, Dilsi y Julia Mora (2015). Estudio de VIH em poblaciones warao y sus determinantes sociales. En Tiempos para pensar: investigación social y humanística en Venezuela. Caracas: Consejo Latinoamericano de Ciencias Sociales.

Secretaría Internacional de Pueblos Indígenas frente al VIH, la Sexualidad y los Derechos Humanos (Sipia) y ONUSIDA (2016). Estado del Arte sobre VIH y Pueblos Indígenas en América Latina. Informe.

Seeger, Anthony, Roberto Da Matta y Eduardo Viveiros de Castro (1979). A construção da pessoa nas sociedades indígenas brasileiras. Boletim do Museu Nacional. Antropologia, 32, 1-19.

Texeira. Léia (2004). A mulher terena em tempos de AIDS: um estudo de caso da aldeia Limão Verde, Município de Aquidauana - MS (dissertação de mestrado em História). Universidade Federal de Mato Grosso do Sul (UFMS)

Unesco (2014). Falando sobre prevenção as DTS/AIDS e hepatites virais Kanamari. Brasilia: Unesco.

Vilaça, Aparecida (2008). Conversão, prestação e perspectiva. MANA, 14(1), 173-204.

Viveiros de Castro, Eduardo (2004). Perspectival anthropology and the method of controlled equivocation. Tipiti: Journal of the Society for the Anthropology of Lowland South America, 2(1), 3-22.

Wiik, Flavio (2001). Contato, epidemias e corpo como agentes de transformação: um estudo sobre a AIDS entre os Índios Xokléng de Santa Catarina, Brasil. Caderno Saúde Pública, 17(2), 397-406, mar-abr.

Zavaleta, Carol, Jaris Mujica, Pedro J. Ypanaqué y Neptalí Cueva (2007). Infecciones de transmisión sexual y VIH/sida en comunidades nativas de la Amazonía peruana: consideraciones culturales. Revista Peruana de Medicina Experimental y Salud Pública, 24(3), https://doi.org/10.17843/rpmesp.2007.243.1126 